LA W RENCE LIVERMORE NATIONAL LABORATORY
A New Approach for the Permanent Disposal of Long Lived Fission Waste

L. John Perkins

March 30, 2007 
This document was prepared as an account of work sponsored by an agency of the United States Government. Neither the United States Government nor the University of California nor any of their employees, makes any warranty, express or implied, or assumes any legal liability or responsibility for the accuracy, completeness, or usefulness of any information, apparatus, product, or process disclosed, or represents that its use would not infringe privately owned rights. Reference herein to any specific commercial product, process, or service by trade name, trademark, manufacturer, or otherwise, does not necessarily constitute or imply its endorsement, recommendation, or favoring by the United States Government or the University of California. The views and opinions of authors expressed herein do not necessarily state or reflect those of the United States Government or the University of California, and shall not be used for advertising or product endorsement purposes.

This work was performed under the auspices of the U.S. Department of Energy by University of California, Lawrence Livermore National Laboratory under Contract W-7405-Eng-48 


\title{
A New Approach for the Permanent Disposal of Long Lived Fission Waste
}

\author{
L. John Perkins \\ Lawrence Livermore National Laboratory \\ March 19, 2003
}

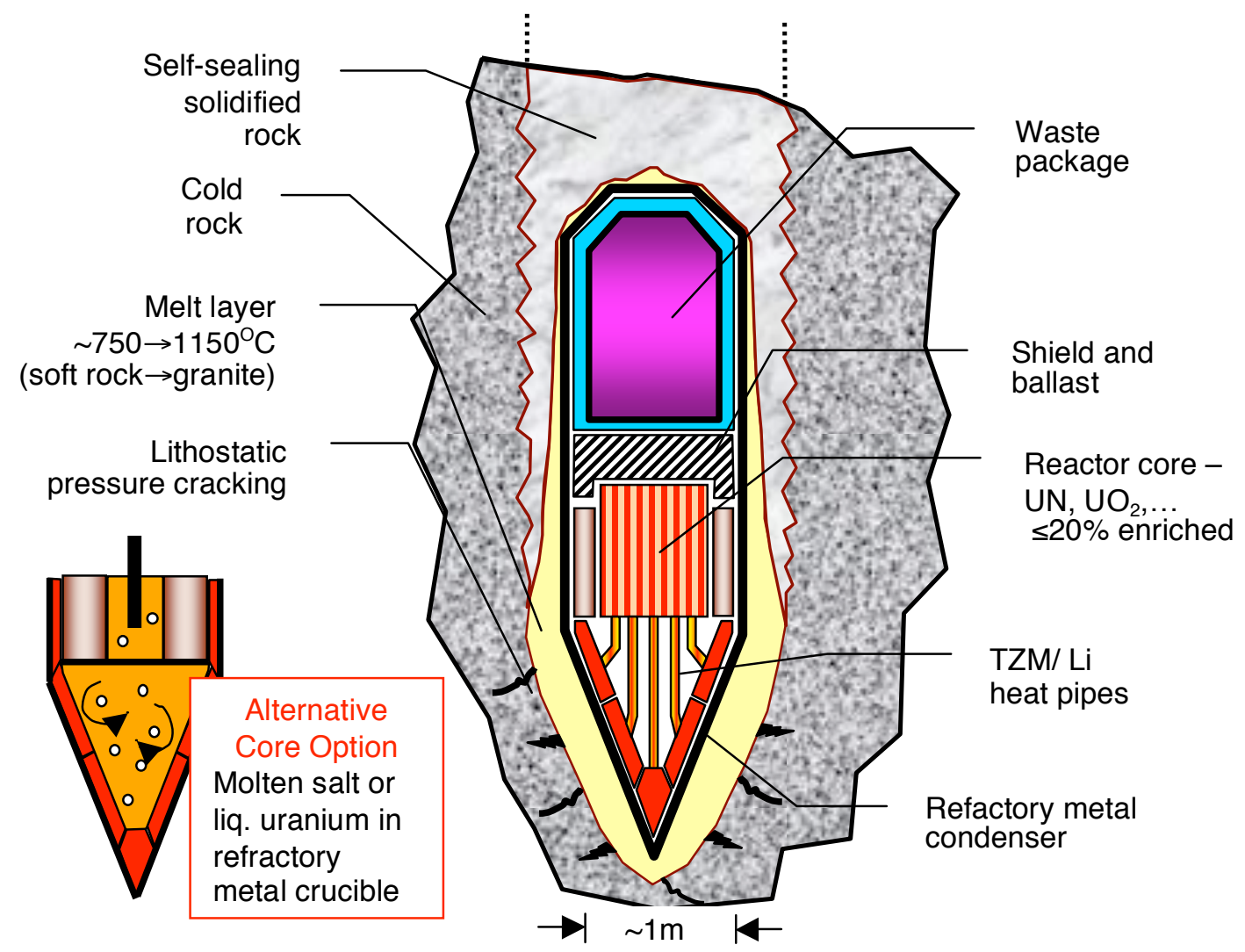

Fig 1. Self-sealing penetrator for permanent disposal of long-lived fission waste

\begin{abstract}
Nuclear fission is capable of meeting global needs for carbon-free energy for millennia. However, the siting and implementation of waste repositories for spent fuel is becoming increasingly problematic from a financial and political perspective. We have performed initial studies of a novel concept for the permanent disposal of longlived fission waste, where "permanent" is defined as being on the billion-year time scale. The concept employs the heat from a compact, high-power-density fission reactor to melt a self-sealing channel, tens of kilometers down into the continental lithosphere. Partitioned long-lived fission waste is packaged at the rear of the device that melts its way through the rock at a descent rate set by the achievable reactor power density. The waste would be irretrievable and cannot return to the biosphere. Monitoring and longterm integrity of waste containers would not be required and disposal costs should be $<1 \%$ of the cost-of-electricity. Design concepts for the reactor and the principle of molten rock boring are based on existing experimental and operational data.
\end{abstract}




\section{Introduction: The Need for Innovative Approaches to Fission Waste Disposal}

Nuclear fission can meet humanity's disparate requirements for carbon-free energy throughout this century and for millennia to come - not only for electricity but also as a source of hydrogen for transportation fuels and a heat source for desalination [1]. However, most countries are not pursuing fission as an option for future energy and global climate needs. One paramount reason is diminished public acceptance over concerns of waste disposal. We would also add "fuel resources" as a major future concern, because fission is not sustainable in the long term with the present "once-through" fuel that utilizes less than $1 \%$ of the mined uranium and consigns its fertile potential to a permanent waste repository [2]. Accordingly, global scale fission will become attainable (i.e., doable) if and when an integrated solution to this overall "fuel-cycle" problem is realized. It is the back-end of the fuel cycle - i.e., the need for permanent storage of spent fuel and high-level waste - that has become the focus of much of the criticism. In particular, the construction and implementation of permanent waste repositories such as Yucca Mountain is becoming increasingly problematic from a financial and political perspective [3]

The major shortcoming of these conventional repositories is that they must accommodate the whole spent fuel output from once-through fuel cycles. They are thus burdened with very large masses of material but where less than $1 \%$ is long-term, hazardous waste and where only a small fraction of the potential nuclear energy has been extracted [4]. Second, such facilities must ensure integrity of waste containment for tens of thousands of years. Given that anything more than a few hundred years hence is unknowable and wholly unpredictable as far as future civilizations are concerned, public perception is that such facilities cannot be guaranteed to be absolutely secure for their envisaged lifetimes of tens of millennia.

\section{Concept Overview}

In the 1960s, Los Alamos pioneered the principle of molten rock boring under their "Subterrene" program [5]. This utilized electrically-heated, refractory metal melt heads with temperatures up to $1500^{\circ} \mathrm{C}$. Melted bore holes of $\leq 10 \mathrm{~cm}$ diameter were experimentally demonstrated in short length samples $(\sim 1-2 \mathrm{~m})$ of hard rock while $5 \mathrm{~cm}$ diameter holes were driven vertically in tuff down to a depth of $82 \mathrm{feet}$, and horizontally to a length of $52 \mathrm{feet}$. The concept was intended to compete with conventional rotary drills for various applications including oil exploration and geothermal prospecting in soft and hard rock environments. This technically successful program terminated in the mid 1970s, leaving a wealth of experimental data on the science of molten rock boring with high-temperature, electrical-heated penetrators.

Meanwhile, in the 1950's -1980's, a variety of concepts were developed and tested for compact, high temperature, fission reactors operating at very high power density [6-9]. Many of these reactors were developed for the space program, either as high power, space-based power supplies in the range 10 's-of- $\mathrm{kW}_{\text {th }}$ to 10 's- $\mathrm{MW}_{\text {th }}$, or for nuclear propulsion at thermal powers of 100 's to 1000 's of $\mathrm{WM}_{\mathrm{th}}$. Very high operating temperatures of $1500-2500^{\circ} \mathrm{C}$, together with power densities spanning $0.01-7 \mathrm{MW}_{\text {th }} /$ liter were achieved in these reactors in steady-state operation.

We propose that these technologies can be combined in a very deep, self-contained earth penetrator, capable of permanently disposing of separated, long-lived waste from advanced, fission fuel cycles. The principle of the device is shown in Fig.1. A small, high-power-density fission reactor supplies heat to a refractory metal "drill" head operating at a surface temperature selected for the rock type, typically $\sim 850-1300^{\circ} \mathrm{C}$ depending on substrata and depth. Partitioned 
long-term fission waste - i.e., long-lived fission products $\left({ }^{99} \mathrm{Tc},{ }^{129} \mathrm{I}, \ldots\right)$ and minor actinides $(\mathrm{Np}$, Am, Cm) - is packaged in the rear of the device. A melt layer of rock slurry develops around the head, spreads along the length and the device then melts its way through the rock with a descent rate set by the achievable reactor power density. Molten rock cools behind the device and seals the descent channel. An appropriate analogy might be a hot ball bearing sinking through a pat of butter. We estimate that descent rates might be of the order of $\sim$ several $\mathrm{mm} / \mathrm{s}-$ that is, several$100 \mathrm{~m} /$ day - and are determined by the volumetric power density of the reactor core relative to the surface heat flux at the head and the rock strata type. The reactor and entrained waste package penetrates tens of $\mathrm{km}$ into the lithosphere over weeks and become locked up at depth.

Permanent disposal sites employing this concept would be situated in the stable regions of the continental lithosphere away from the boundaries of the tectonic plates. Ideally, such sites would be central components of large scale, integrated fission energy parks - see Fig. 2. Note that the only commodity entering the site is raw fuel stock - i.e., uranium for the $\mathrm{U}^{239} \mathrm{Pu}$ fuel cycle or thorium for the $\mathrm{Th}-{ }^{233} \mathrm{U}$ cycle - and the only products leaving are electricity and process heat products such as hydrogen fuel production and desalinated water. All operations are closed on site, including fuel fabrication, breeding, energy production, reprocessing, waste partitioning and waste disposal. No waste or fissionable material leaves the site security boundary, thus proliferation risks are minimized. A typical $1000 \mathrm{MW}_{\mathrm{e}}$ reactor produces only several tons of (partitioned) long-lived waste over a 30year lifetime (i.e., $<1 \%$ of total discharge mass) and could be accommodated by just one penetrator of diameter $\sim 1 \mathrm{~m}$. Consequently, the economics of the entire disposal system should be modest and should comprise less than $1 \%$ of the cost of electricity over the lifetime of a typical $1000 \mathrm{MW}_{\mathrm{e}}$ power plant.

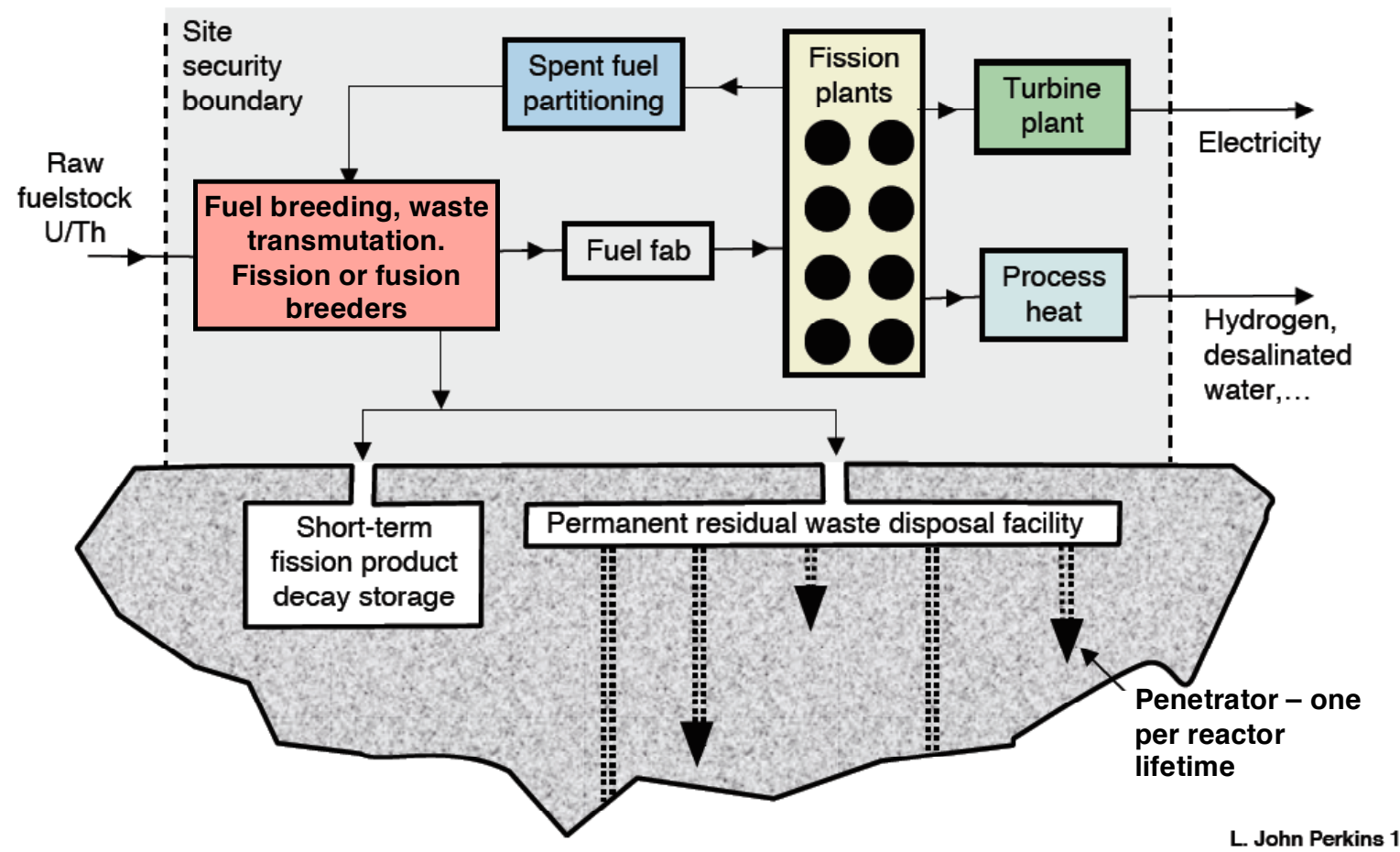

Fig2. This concept could be integrated in future fission reservations. All operations are closed on site, including fuel fabrication, breeding, energy production, reprocessing, waste partitioning and waste disposal. In this closed partitioned fuel cycle, the spent fuel is reprocessed to recycle the plutonium and unburnt uranium. Short-lived fission products $\left({ }^{137} \mathrm{Cs},{ }^{90} \mathrm{Sr}, ..\right)$ are sent to temporary storage while long-lived fission products $\left({ }^{99} \mathrm{Tc},{ }^{129} \mathrm{I}, \ldots\right)$ and minor actinides $(\mathrm{Np}, \mathrm{Am}$, $\mathrm{Cm}$ ) are sent to permanent disposal via the penetrator (one device per $1000 \mathrm{~W}_{e}$ reactor lifetime) 
The ages of the middle regions of the major continental tectonic plates are in vicinity of 1-2 billion years [10]. So, whereas volcanoes and seismic activity occur in conjunction with the formation processes at the edges of the plates, the interior regions of much of the continents are quiescently stable on this timescale. Radioactive waste deposited at depth in these regions is, therefore, locked away for times longer than any scale of concern regarding the biological security of the waste.

A question in the application of this technology concerns the consequence of radionuclide deposition at depth relative to the local environment. It turns out that approximately $75 \%$ of the geothermal heat in the earth arises from radioactive decay of naturally occurring long-lived nuclides, mainly ${ }^{238} \mathrm{U},{ }^{235} \mathrm{U},{ }^{232} \mathrm{Th}$ and ${ }^{40} \mathrm{~K}$, with the balance due to the earth's primordial formation energy [11]. Moreover, this radiogenic heat is not produced uniformly through the bulk earth but is strongly peaked towards the upper regions because of the spatial concentration of elements. Accordingly, we can show that the equilibrium disposal of partitioned waste from a sustainable world fission economy for millennia would result in a negligible addition to this natural radionuclide content that has been resident for several billion years.

Compared with conventional, near-surface mined repositories for once-through fuel cycles, we suggest this concept may offer the following potential advantages:

- Stable on the billion-year time scale; impossible to return to the biosphere

- Irretrievable - no need to guard forever (sink and forget)

- Permanent disposal mass per $\mathrm{MW}_{\mathrm{th}}$-year of fission energy generation is reduced by more than two orders of magnitude.

- Long-term integrity of waste containers at depth not required

- Issues of short-term decay heat removal are decoupled from those of long-term disposal

- Lower cost per $\mathrm{MW}_{\text {th }}$-year of generated fission energy.

- Can be integrated on-site with fission energy parks so that a separate central repository is not required, thus eliminating diversion risks during transport

\section{Relationship of this Concept to the Yucca Mountain Project}

The R\&D for Yucca Mountain is technically mature and the facility is ready to proceed [4]. By contrast, the concept of this paper, even when demonstrated to be a practical technology, would have to await the arrival of full partitioned fuel cycle in the future. Thus these two disposal paradigms can be considered complementary. Conventional, near-surface repositories appear to be the best short-term solution and should proceed without delay. Then, as breeder fission systems come on line, disposal could switch to this concept. And, if desired in the future, the once-through spent fuel inventories could be retrieved from near-surface repositories, the waste partitioned, and long-lived nuclides ultimately disposed of by this technique. Very importantly, Yucca Mountain then only needs to be a short term ( 100-year) facility.

\section{References}

1. R. Krakowski, R.Wilson "What Can Nuclear Power Accomplish?", p211 in Innovative Energy Strategies for CO2 Stabilization, R.G.Watts (Ed), Cambridge University Press (2002)

2 M. Hori et al, "Long Term Global Energy Perspective and Fast Reactor Development", Global 99: Proc Internat Conf on Future Nuclear Energy Systems, , American Nuclear Society (1999) 
3. M. Kritz "Congress: Going Nuclear”, National Journal, 1141, April 202002

4 DOE Office of Civilian Radioactive Waste Management, "The Yucca Mountain Project" http://www.ocrwm.doe.gov/ymp US Department of Energy (2003)

5. J.C.Rowley, “The Subterrene Program”, Mini-Review-73-1, LANL (1973)

6. F.J.Gardner, "Nuclear Power for Deep Space Missions”, J. Brit, Interplan Soc., 47215 (1994)

7. NRC Committee on Advanced Nuclear Systems, Proc Symp on Advanced Compact Reactor Systems, Washing DC, November 15, 1982 (1982)

8 V.V.Trucello, L.L.Rutger "The SP-100 Power System", in Proc. Ninth Symp. on Space Nuclear Power Systems, AIP 246, American Institute of Physics, New York (1992)

9. E.S.Bettis et al, "The Aircraft Reactor Experiment”, Nucl Sci Eng, 2804 (1957)

10 M.K.McNutt, "Lithospheric Plates" p675 in Encylopedia of Earth System Science, William A. Nierenberg (ed), Academic Press (1992)

11. G.R.Beardsmore, J.P.Cull "Crustal Heat Flow" Cambridge University Press (2001)

12. L.J.Perkins, "A New Approach for the Permanent Disposal of Long-Lived Fission Waste", to be published (2007)

\section{Acknowledgements}

The author is pleased to acknowledge valuable discussions with H.Hopkins, L.Fischer, R.Moir, C.Walter, D.Voght, J.Smith, L.Glenn, F.Ryerson, D.Farber, B.Bonner 